\title{
GENOTIPIFICACIÓN DEL GEN MSP3 EN PACIENTES CON MALARIA COMPLICADA
}

\section{GENOTYPIFICATION OF THE MSP3 GENE IN PATIENTS WITH COMPLICATED MALARIA}

\author{
Yeiner Espitia D ${ }^{1}$, Carlos Castro $C^{2}$, Virginia Rodríguez $\mathrm{R}^{3}$, Luis Causil ${ }^{4}$, María Camila Velasco $\mathrm{P}^{5}$, Gustavo \\ Quintero $\mathrm{P}^{6}$, María FernandaYasnot $\mathrm{A}^{7 *}$
}

Recibido para publicación: Septiembre 12 de 2017 - Aprobado para publicación: Noviembre 17 de 2017

\begin{abstract}
RESUMEN
Objetivo. Se estudió la diversidad genética de las poblaciones naturales de parásitos de Plasmodium vivax mediante el estudio de la región variable del gen Pvmsp-3 $\alpha$. Materiales y métodos. Se realizó PCR-RFLP en 29 muestras de pacientes con malaria por $P$. vivax con complicaciones (PC) y 32 pacientes con malaria por $P$. vivax sin complicaciones (PNC), todas los pacientes provenientes de la región Bajo-Córdoba-Uraba, zona altamente endémica para malaria. Fueron colectadas muestras de sangre total para la extracción de DNA utilizando la tecnica saponina/chelex-100. Se usó la tecnica de RFLP usando las enzimas de restricción HhAl y Alul. Diez patrones de restricción fácilmente distinguibles, se detectaron después que los productos de la PCR fueron digeridos con la enzima Alu I y 9 con la enzima Hha $I$. Resultados. El gen Pvmsp-3a exhibió gran polimorfismo y los resultados sugieren que este gen puede ser utilizado en Colombia como un marcador molecular epidemiológico para el genotipado de P.vivax., ademas el patron $\mathrm{PH} 1$ con la enzima Alul mostró mayor frecencia en los pacientes complicados. Conclusiones. El gen Pvmsp $3 \alpha$ puede ser un marcador genetico de variabilidad en las cepas circulantes de P.vivax y el PH1 sugiere ser un marcador para predecir una complicación en pacientes con malaria vivax.
\end{abstract}

Palabras clave: Malaria, Plasmodium vivax, complicaciones, genotipificación.

\begin{abstract}
Objective. The genetic diversity of the natural populations of Plasmodium vivax parasites was studied by studying the variable region of the Pvmsp- $3 \alpha$ gene. Materials and methods. PCR-RFLP was performed in 29 samples of patients with P. vivax malaria with complications (PC) and 32 patients with P. vivax malaria without complications (PNC), all patients from the Bajo-Córdoba-Uraba region, Highly endemic to malaria. Total blood samples were collected for DNA extraction using the saponin / chelex-100 technique. The RFLP technique was used using the restriction enzymes HhAl and Alul. Ten easily distinguishable restriction patterns were detected after the PCR products were digested with the enzyme Alu I and 9 with the enzyme Hha I. Results. The Pvmsp-3 $\alpha$ gene exhibited large polymorphism and the results suggest that this gene can be used in Colombia as a molecular epidemiological marker for the genotyping of $P$. vivax. Furthermore, the PH1 pattern with the Alul enzyme showed higher frequency in the complicated patients. Conclusions. The Pvmsp3 gene may be a genetic marker of variability in the circulating strains of $\mathrm{P}$. vivax and the $\mathrm{PH} 1$ suggests a marker for predicting a complication in patients with vivax malaria.
\end{abstract}

KeyWords: Malaria, Plasmodium vivax, complications, genotyping.

${ }^{1}$ Estudiante de pregrado programa de bacteriología, Universidad de Córdoba, Grupo de Investigaciones Microbiológicas y Biomédicas de Córdoba.

${ }^{2}$ Profesor catedrático, Magisteren Microbiología Tropical, programa de bacteriología, Universidad deCórdoba, Grupo de Investigaciones Microbiológicas y Biomédicas de Córdoba.

${ }^{3}$ Profesor titular, Magister en Microbiología, programa de bacteriología, Universidad de Córdoba, Grupo de Investigaciones Microbiológicas y Biomédicas de Córdoba.

${ }^{4}$ Profesor catedrático, estudiante de maestría en Microbiología Tropical, Universidad de Córdoba, Grupo de Investigaciones Microbiológicas y Biomédicas de Córdoba.

${ }^{5}$ Asistente de investigación, Bacterióloga, programa de bacteriología, Universidad de Córdoba, Grupo de Investigaciones Microbiológicas y Biomédicas de Córdoba.

${ }^{6}$ Profesor catedrático, Magister en MicrobiologíaTropical, programa de bacteriología, Universidad deCórdoba, Grupo de Investigaciones Microbiológicas y Biomédicas de Córdoba.

7 Profesor asociado, doctora en Ciencias Biomédicas, programa de bacteriología, Universidad de Córdoba, Grupo de Investigaciones Microbiológicas y Biomédicas de Córdoba. Correo: *myasnot@correo.unicordoba.edu.co 


\section{INTRODUCCIÓN}

Infección del ser humano por especies del género Plasmodium se denomina paludismo o malaria. La importancia de esta enfermedad está determinada por su alta incidencia y gravedad. El número de casos en el mundo oscila entre 300 y 500 millones al año, correspondiendo la mayor parte deestos a áreas endémicas con una elevada mortalidad global, la cual oscila entre 0.6 y $3.8 \%$, incrementándose en embarazadas hasta $13 \%$ y en el anciano hasta $20 \%(1)$.

Enlamalariahumana, la respuesta inmunepuede ocasionar la eliminación del agente infeccioso o una respuesta persistente mediada por citoquinas que conduce a la inmunopatología, con las células $T$ y la activación de macrófagos. Aunquelos mecanismos son muy complejos, los altos niveles de citoquinas pro-inflamatorias, como el factor de necrosis tumoral (TNF), interferón- $\gamma$ (IFN- $\gamma$ ) y la interleucina-6 (IL-6) se han asociado con patologías graves (2), mientras que los niveles bajos de citoquinas reguladoras, tales comoTGF- $\beta$ y IL-10, se han asociado con malaria aguda (Hansen et al, 2010). La citoquina IL-10 tiene un papel importante como un inmunorregulador de las infecciones causadas por Plasmodium, mediante la neutralización de los efectos de las otras citoquinas producidas por las células Th1 y CD8, que son responsables degranparte dela inmunopatología asociada a la sobreproducción de IFN- $\gamma$ ( 3).

En la malaria causada por $P$. vivax, las citoquinas son liberadas después de la ruptura de esquizontes y se han detectado niveles elevados de TNF después de la liberación, lo que parece estar relacionado con la fiebre palúdica. Otras citoquinas que han sido detectadas en malaria por P.vivax son IL-1 $\beta$, IL-2, IL-4, IL-6, IL-8, IL-10 e IL-12 (4, 5,6,7). Se ha demostrado la participación de células $T$ reguladoras en la infección por P.vivax (8), lo que sugiere que se requiere el equilibrio entre citoquinas pro y antiinflamatorias para controlar las alteraciones patológicas; por ende la mayor parte de los estudios en inmunopatogenia de malaria, se centran en la identificación de uno o un pequeño grupo de moléculas relacionadas con la gravedad de la enfermedad. $(9,10)$.

Por otro lado, para entender los efectos de la malaria sobrela fisiopatología de los pacientes, es necesario comprender también la estructura genética -poblacional del parasito. Uno de los marcadores moleculares más utilizados para estudiar la variabilidad de P. vivax es el gen PvMSP- $3 \alpha$ que codifica una proteína con un peso molecular que oscila desde 148 hasta 150 $\mathrm{kDa}(11,12)$. Este gen es altamente polimórfico y su variabilidad ha sido examinada usando la técnica PCR-RFLP, evidenciando que los productos de la amplificación demuestra un alto polimorfismo, debido a que la digestión con endonucleasas de restricción, proporciona fragmentos de varios tamaños, lo que indica la presencia de un gran número de alelos $(13,14)$.

El estudio de la relación entre los grupos de moléculas asociadas a la gravedad de la malariay la estructura genética de la población de Plasmodium, puede contribuir a una mejor comprensión de los patrones de susceptibilidad a la gravedad de la malaria, por tal razón el objetivo de este estudio fue determinar los efectos de la malaria sobre la fisiopatología y su relación con los genotipos de parásitos circulantes en pacientes hospitalizados en el Hospital San Jerónimo de Montería, Colombia.

\section{METODOLOGÍA}

\footnotetext{
Área de estudio, tipo y diseño general del estudio

El estudio sellevó a cabo en municipios de áreas endémicas para malaria en el departamento de Córdoba. Este estudio es de tipo descriptivo analítico, en él se identificaron los distintos genotipos, para el gen Pvmsp-3 $\alpha$, presentes en los parásitos responsables de la malaria por Plasmodiumvivaxen las áreas geográficas que abordó el estudio.
} 
Población de estudio.

Para la caracterización sociodemográfica y clínica (signos y síntomas) de la población de estudio se plantea hacer un estudio descriptivo prospectivo. La caracterización inmunológica se realizará mediante un estudio de tipo prospectivo, analítico.

El estudio será realizado en dos grupos de individuos que acuden a los diferentes hospitales de los municipios estudiados, se incluirán todos los grupos, previo consentimiento informado.

El grupo 1. Correspondió a pacientes con malaria, quienes no tengan ningún signo de complicación.

Grupo 2. Pacientes ingresados a hospitalización, con algún signo de complicación.

\section{Muestra.}

Para la obtención de ADN parasitario, se tomaron 70 muestras de sangre periférica en papel filtro tipo Whatman $\mathrm{N}^{\circ} 3$ de pacientes infectados por Plasmodium vivax hospitalizados en la E.S.E Hospital San Jerónimo de Montería, provenientes de diferentes municipios de los departamentos de Córdoba: Tierra Alta, Ayapel, Puerto Libertador, La Apartada, Valencia, Montelibano, y Planeta Rica, en el y departamento de Antioquia: Apartadó, San Juan de Urabá y Arboletes. Previo a la toma de la muestra, los pacientes fueron informados del propósito de la investigación y dieron su consentimiento por escrito.

Para mantener la confidencialidad de la información del paciente, a cada muestra sele asignó un código, representado por una letra (correspondiente a la inicial del nombre de su municipio de procedencia) y un número correlativo, de forma que la información no guardara vínculo alguno con la identidad del paciente.

El análisis de muestras e información, se realizó bajo los lineamientos establecidos por la Declaración de Helsinki y sus enmiendas, y no conllevó riesgo para la integridad física y mental de los participantes, como tampoco para el medio ambiente.

De las muestras obtenidas, se escogieron para su análisis unicamente las muestras que cumplieron con los siguientes criterios de selección:

> Diagnóstico microscópico positivo para monoinfección por P.vivax; noseanalizaron las muestras con infecciones asociadas (P.vivax-P.falciparum), ni con infecciones por P.falciparum.

> Parasitemia mayor a 25 formas asexuadas por cada 1.000 leucocitos.

Infección por $P$. vivax y estimación de la densidad parasitaria

La confirmación microscópica de infección por $P$. vivax y la estimación de la densidad parasitaria se realizó de acuerdo con la definición del Protocolo de Vigilancia y Control de Malaria del Instituto Nacional de Salud (INS) de Colombia (15).

\section{Extracción de ADN parasitario}

La extracción de DNA parasitario se realizó a partir de muestras de sangre contenidas en papel de filtro (Watman 3), usando el método de Chelex/Saponina (Guerra et al., 2006). Esta técnica consistió en cortar un icha clínica completamente diligenciada pedazo de la muestra obtenida en papel filtro, se adicionó $1 \mathrm{ml}$ de PBS $1 \mathrm{X}$ y $50 \mu \mathrm{l}$ de saponina al $10 \%$ e incubó durante toda la noche a $4^{\circ} \mathrm{C}$. Al día siguientesecentrifugaron los tubosa $10000 \mathrm{rpm}$ por 5 minutos $4^{\circ} \mathrm{C}$, posteriormentesedescartó el sobrenadante y se agregó $1 \mathrm{ml}$ de solución salina amortiguada con fosfatos (PBS) $1 \mathrm{X}$ por 30 minutos a $4^{\circ} \mathrm{C}$; se centrifugó a $10000 \mathrm{rpm}$ por $5 \min$ a $4^{\circ} \mathrm{C}$, luego se aspiró tanto líquido cómo fue posible y se descartó, con la misma punta se llevó el papel al fondo del tubo sin empaquetar. Posteriormente se adicionó $100 \mu \mathrm{l}$ 
de $\mathrm{H}_{2} \mathrm{O}$ milli $\mathrm{Q}$ a cada tubo; luego se adicionó $50 \mu \mathrm{l}$ de Chelex a cada tubo para extraer el ADN de la muestra y se incubaron los tubos con la mezcla a $95^{\circ} \mathrm{C}$ por $10 \mathrm{~min}$, se mezcló fuertemente con vortex con intervalos de $2 \mathrm{~min}$ durante toda la incubación; se centrifugaron los tubos a 13000 rpm por 5 min a temperatura ambiente $\left(\sim 25^{\circ} \mathrm{C}\right)$; luego se transfirió toda la solución a un tubo marcado $(A)$, sin destruir el papel; nuevamente se centrifugaron los tubos $A$ a 13000 rpm por 5 min a temperatura ambiente $\left(\sim 25^{\circ} \mathrm{C}\right)$ y se transferíó el sobrenadante a un tubo $B$ sin tomar el Chelex que se encuentra en el fondo. El ADN se distribuyó en alícuotas de $30 \mu \mathrm{l}$ y se almacenó a $-20^{\circ} \mathrm{C}$ hasta el momento dela realización de las pruebas moleculares. La integridad delADNseverificóporelectroforesis en gel de agarosa al $2 \%$ en buffer TBE $1 \mathrm{X}$.

\section{Confirmación molecular de infección por Plasmodium vivax}

Debido a que la extracción se realizó a partir de sangre total, tanto el ADN del huésped como del parásito están presentes. Para confirmar la presencia de ADN de P.vivax de cada una de las extracciones, se realizó una amplificación por Nested-PCR. En el primer PCR se amplificó un segmento del gen $18 \mathrm{~S}$ del RNA ribosomal (SSUrRNA) especifico del género Plasmodium y a partir del producto de amplificación de esta primera reacción se realizó un segundo PCR (PCR múltiple) especifico para las especies Plasmodium vivax y Plasmodium falciparum. Los "primers" usados y las condiciones seguidas fueron las de Roshanravan y col. (2003), con algunas modificaciones.

\section{Genotipificación de las muestras} La genotipificación de P.vivax se realizó mediante elprotocolodePCR-RFLPdescritopor Zakerietal (2006) con modificaciones, para la cual se utilizó como marcador molecular el gen Pvmsp-3 $\alpha$, que codifica la proteína $3 \alpha$ de la superficie del merozoíto del parásito (MSP3- $\alpha$ ); este marcador ha sido usado en otras investigaciones en zonas endémicas de Sudamérica como en nuestro país (16), Perú (17) y en Brasil (18), también en lugares como Tailandia (19), Papúa Nueva Guinea (20) y la India (21). Las secuencias, los oligonucleótidos y las condiciones de reacción y amplificación fueron adaptadas a partir de estos estudios epidemiológicos.

La digestión enzimática se realizó a partir de los productos de amplificación provenientes de la segunda PCR del nested PCR, con las enzimas de restricción denominadas Alu I y Hha I (New England BIOLabs), las cuales se logró establecer el polimorfismo dela longitud de los fragmentos de restricción o RFLP, ampliamenteutilizadas para estudios de genotipificación como los efectuados en Colombia (16), Iquitos (Perú) (17), y Brasil (18). Para la reacción de digestión se usó $5 \mu \mathrm{l}$ del producto amplificado (ADN) conteniendo 10 unidades de enzima/reacción, en un volume de reacción de $15 \mu$ y se incubó a $37^{\circ} \mathrm{C}$ por $4-5$ horas. Los productos obtenidos (fragmentos de digestión) sevisualizaron en gel de agarosa al 2,5\%, conteniendo 0,05 $\mu \mathrm{g}$ de bromuro de etidio $(1 \mu \mathrm{g} / \mathrm{mL})$. Se determinó los tamaños de los fragmentos usando un marcador de peso molecular de $100 \mathrm{pb}$. Los patrones enzimáticos fueron designados con base en el tamaño de los fragmentos como haplotipos PA para Alu I y PH para Hha I. Se identificó las infecciones policlonales por la presencia de dos o más secuencias alélicas del producto de PCR; sien la misma muestra se presentan ambos fragmentos, se asume que es una infección múltiple (por más de un clon de P.vivax), pero si se presenta sólo uno (cualquiera que sea) se asume que es una infección por un solo clon.

Posteriormente, los fragmentos fueron digeridos con las enzimas de restricción Alu I y Hha I en reacciones independientes. Si la infección es por un único clon, la suma de los fragmentos debe ser igual al tamaño del producto sin digerir; si por el contrario, la suma de los fragmentos es mayor a la del fragmento sin digerir, se trata de una infección múltiple. 


\section{Visualización de los productos de PCR}

Para visualizar los productos de amplificación de las PCR realizadas, se usaron geles de agarosa al $2 \%$. Los geles se tiñeron con bromuro de etidio $(1 \mu \mathrm{g} / \mathrm{ml})$ y se visualizaron bajo luz ultravioleta; el tamaño de los productos se determinó usando un patrón de peso molecular de $100 \mathrm{pb}$ (Promega $\left.{ }^{\circledR}\right)$. Los resultados se registraron en el analizador de imágenes Gel Doc $X R \circledast$ usando el software Quality one, versión 4.6.2 para Windows $\AA$ de Bio-Rad $\circledast$.

\section{Análisis estadístico}

Se evaluó la asociación entre los patrones de restricción identificados y las variables clínico epidemiológicas de los pacientes (género, edad), grado de infección que presentaban y área geográfica de procedencia dela infección, a través de la prueba de Fisher, con un nivel de confianza del $95 \%$.

\section{Aspectos éticos}

Para todos los procedimientos se tuvieron en cuenta las consideraciones éticas y los principios de la declaración de Helsinki (World Medical Association; 2000), las normas del Ministerio de Salud de Colombia, Resolución 008430 de 1993 (Ministerio de Salud. Dirección de desarrollo científico y tecnológico. Normas científicas, técnicas y administrativas para la investigación en salud). Resolución No. 008430 de 1993. Santafé de Bogotá: Imprenta Nacional; 1993). Se elaboró de acuerdo con lo estipulado en esta resolución, un documento que fue entregado, previa lectura yexplicación de la naturaleza, beneficios y riesgos de la participación en el estudio, a cada uno de los pacientes elegibles o a sus padres en caso de ser menores de edad, y un formato en el que el paciente elegible o su padre o adulto confirmó, mediantesufirma, su disposición de participar.

\section{RESULTADOS}

Características demográficas y clínicas de la población de estudio.

En el estudio se incluyeron 29 pacientes hospitalizados de diferentes localidades del departamento de Córdoba y 32 pacientes no hospitalizados provenientes del municipio de Tierralta. En la tabla 1, se muestran las características clínicas y demográficas de los pacientes. En las muestras provenientes de pacientes con malaria complicada el promedio de parasitemia fue de $15.600 \mathrm{p} / \mathrm{uL}$ con un rango entre $500-32.000 \mathrm{p} /$ $\mathrm{uL}$ y en las muestras provenientes de pacientes con malaria no complicada el promedio de parasitemia fue de $12.700 \mathrm{p} / \mathrm{uL}$ con un rango entre 80-22000 p/uL observandose una diferencia marcada entre los promedios de densidad parasitaria entre los dos grupos.

Tabla 1. Características demográficas y clínicas de los pacientes en estudio.

\begin{tabular}{|c|c|c|}
\hline Característica & $\begin{array}{l}\text { Grupo } \\
\text { Pacientes n (29) }\end{array}$ & $\begin{array}{l}\text { Grupo } \\
\text { controln (32) }\end{array}$ \\
\hline \multicolumn{3}{|l|}{ Edad } \\
\hline $1-18$ & $15(56,8 \%)$ & $20(54,1 \%)$ \\
\hline $19-59$ & $13(40,5 \%)$ & $11(43,8 \%)$ \\
\hline$>=60$ & $1(2,7 \%)$ & $1(2,1 \%)$ \\
\hline \multicolumn{3}{|l|}{ Sexo } \\
\hline Femenino & $10(40,5 \%)$ & $13(27,1 \%)$ \\
\hline Masculino & $19(59,5 \%)$ & $19(72,9 \%)$ \\
\hline Cefalea & $29(100 \%)$ & $48(100 \%)$ \\
\hline Fiebre & $29(100 \%)$ & $48(100 \%)$ \\
\hline Escalofríos & $29(100 \%)$ & $32(100 \%)$ \\
\hline Nauseas & $25(94,6 \%)$ & $8(27,1 \%)$ \\
\hline Dolores articulares & $24(86,5 \%)$ & $5(18,8 \%)$ \\
\hline Diarrea & $21(83,8 \%)$ & $2(8,3 \%)$ \\
\hline Vomito & $20(81,1 \%)$ & $4(12,5 \%)$ \\
\hline Convulsiones & $1(2,7 \%)$ & 0 \\
\hline Falla renal & $1(2,7 \%$ & 0 \\
\hline Falla respiratoria & $9(24,3 \%)$ & 0 \\
\hline
\end{tabular}


Análisis del polimorfismo genético en la longitud de los fragmentos de restricción (RFLP) del gen Pvmsp 3 $\alpha$, usando la enzima Alu I en muestras de pacientes complicados y no complicados.

Diez patrones de restricción fácilmente distinguibles patrones se detectaron después que los productos de la PCR fueron digeridos con la enzima Alu I), observándose fragmentos con tamaños que varian entre 130-600 pb. Los fragmentosque mostraron un tamaño inferior a
100 pbnoseincluyeronparadiferenciarpatrones de restricción ya que nuestras condiciones de electroforesis no permitían que estas bandas que se resolvieron con claridad. El patrón PA1 predominó, al ser observado en el 34,4\% (10 129) de las muestras a partir de pacientes con malaria complicada con infecciones simples (tabla 2). Por el contrario, los patrones PA4 y PA6 fueron los mas frecuentes en muestras de pacientes No complicados (tabla 3).

Tabla 2. Patrones de restricción del gen Pvmsp3 $\alpha$ obtenidos con la enzima Alu l (PA) en pacientes complicados.

\begin{tabular}{|l|l|l|}
\hline $\begin{array}{l}\text { Patrones de restricción del gen Pvmsp3 } \alpha \\
\text { obtenidos con la Enzima Alu I (PA) }\end{array}$ & $\begin{array}{l}\text { Tamaño de bandas en pares de } \\
\text { bases }(\mathbf{p b})\end{array}$ & $\begin{array}{l}\text { Frecuencia de Pacientes }(\% \text { con } \\
\text { respecto al total de pacientes) }\end{array}$ \\
\hline PA1 & $530,28,200,180$ & $10(34,4 \%)$ \\
\hline PA2 & $800,530,28,200,180$ & $2(6,7 \%)$ \\
\hline PA3 & $800,530,450,200,180$ & $2(6,7 \%)$ \\
\hline PA4 & $530,360,280,200,180$ & $3(10,3 \%)$ \\
\hline PA5 & $700,530,360,280,200,150$ & $2(6,7 \%)$ \\
\hline PA6 & $530,400,360,280,200,150$ & $3(10,3 \%)$ \\
\hline PA7 & $500,360,200,150$ & $2(6,7 \%)$ \\
\hline PA8 & $750,500,400,280,200,150$ & $2(6,7 \%)$ \\
\hline PA9 & 530 & $2(6,7 \%)$ \\
\hline PA10 & 500 & $\mathbf{1}(3,44 \%)$ \\
\hline TOTAL: 10 patrones & & $29(100 \%)$ \\
\hline
\end{tabular}

Tabla 3. Patrones de restricción del gen Pvmsp3a obtenidos con la enzima Alu I (PA) en pacientes No complicados.

\begin{tabular}{|l|l|l|}
\hline $\begin{array}{l}\text { Patrones de restricción del gen Pvmsp3 } \alpha \\
\text { obtenidos con la Enzima Alu I (PA) }\end{array}$ & $\begin{array}{l}\text { Tamaño de bandas en pares de } \\
\text { bases (pb) }\end{array}$ & $\begin{array}{l}\text { Frecuencia de Pacientes (\% con } \\
\text { respecto al total de pacientes) }\end{array}$ \\
\hline PA1 & $530,80,200,180$ & $\mathbf{2}(6,3 \%)$ \\
\hline PA4 & $530,360,80,200,180$ & $\mathbf{1 1}(34,4 \%)$ \\
\hline PA5 & $700,530,360,280,200,150$ & $\mathbf{2}(6,3 \%)$ \\
\hline PA6 & $530,400,360,280,200,150$ & $10(31,3 \%)$ \\
\hline PA7 & $500,360,200,150$ & $\mathbf{2 ( 6 , 3 \% )}$ \\
\hline PA8 & $750,500,400,280,200,150$ & $\mathbf{1}(3,1 \%)$ \\
\hline PA10 & $600,530,500,200,180,150$ & $\mathbf{5 ( 1 5 , 6 \% )}$ \\
\hline TOTAL: 10 patrones & & $\mathbf{3 2}(100 \%)$ \\
\hline
\end{tabular}


Análisis del polimorfismo genetico en la longitud de los fragmentos de restricción (RFLP) del gen Pvmsp 3 $\alpha$, usando las enzimas HhA I en muestras de pacientes complicados y no complicados.

Se observaron fragmentos entre $190-1.000 \mathrm{pb}$ después de la digestión de los productos de PCR con la enzima Hha $I$, y todas las bandas se utilizaron para el establecimiento de los patrones. Se encontraron nueve diferentes patrones de restricción.
Los patrones $\mathrm{PH} 2, \mathrm{PH} 3$ y $\mathrm{PH} 4$ predominaron, al ser observados con el 17,2\%, 17,2\% y $20,7 \%$ respectivamente, de las muestras con infecciones simples (tabla 4).

En las muestras a partir de pacientes con malaria no complicada, el patrón encontrado con mayor frecuencia fue el $\mathrm{PH} 4$ con el 31,2\% $(10 / 32)$ (tabla 5).

Tabla 4. Patrones de restricción del gen Pvmsp3 $\alpha$ obtenidos con la enzima Hhal $(\mathrm{PH})$ en muestras de pacientes complicados.

\begin{tabular}{|l|l|l|}
\hline $\begin{array}{l}\text { Patrones de restricción del gen Pvmsp3 } \\
\text { obtenidos con la Enzima } \mathbf{H h a} \text { I (PH) }\end{array}$ & $\begin{array}{l}\text { Tamaño de bandas e pares de } \\
\text { bases (pb) }\end{array}$ & $\begin{array}{l}\text { Frecuencia de Pacientes (\%con respecto } \\
\text { al total de pacientes) }\end{array}$ \\
\hline P1 & $1,000,480,330$ & $\mathbf{3}(10.3 \%)$ \\
\hline PH2 & $, 00,480,400$ & $\mathbf{5}(17,2 \%)$ \\
\hline PH3 & $1,000,510,400$ & $\mathbf{5}(17,2 \%)$ \\
\hline PH4 & $1,000330,280,200$ & $\mathbf{6}(20,7 \%)$ \\
\hline PH5 & $1,000480,280,180$ & $\mathbf{3}(10.3 \%)$ \\
\hline PH6 & $1,000,600,330$ & $\mathbf{1}(3,8 \%)$ \\
\hline PH7 & $1,000,480$ & $\mathbf{3}(10.3 \%)$ \\
\hline PH8 & 1,000 & $\mathbf{2}(6,9 \%)$ \\
\hline PH9 & $1,000,510,480$ & $\mathbf{1}(3,4 \%)$ \\
\hline TOTAL: 9 patrones & & $\mathbf{2 9}(100 \%)$ \\
\hline
\end{tabular}

Tabla 5. Patrones de restricción del gen Pvmsp3 $\alpha$ obtenidos con la enzima Hhal (PH) en muestras de pacientes no complicados.

\begin{tabular}{|l|l|l|}
\hline $\begin{array}{l}\text { Patrones de restricción del gen Pvmsp3 } \alpha \\
\text { obtenidos con la Enzima Hha I }(\mathbf{P H})\end{array}$ & $\begin{array}{l}\text { Tamaño de bandas en pares de } \\
\text { bases }(\mathrm{pb})\end{array}$ & $\begin{array}{l}\text { Frecuencia de Pacientes }(\% \text { con } \\
\text { respecto al total de pacientes) }\end{array}$ \\
\hline PH1 & $1,000,480,330$ & $\mathbf{5}(16.1 \%)$ \\
\hline PH2 & $1,000,480,400$ & $\mathbf{5}(16.1 \%)$ \\
\hline PH3 & $1,000,510,400$ & $6(18,7 \%)$ \\
\hline PH4 & $1,000330,280,200$ & $10(31,2 \%)$ \\
\hline PH5 & $1,000480,280,180$ & $\mathbf{3}(9.3 \%)$ \\
\hline PH6 & $1,000,600,330$ & $\mathbf{1}(3,1 \%)$ \\
\hline PH7 & $1,000,480$ & $\mathbf{2}(6.2 \%)$ \\
\hline TOTAL: 9 patrones & & $\mathbf{3 2}(100 \%)$ \\
\hline
\end{tabular}




\section{DISCUSIÓN}

A pesar de que Plasmodium vivax es el responsable de más del $80 \%$ de los casos de malaria en el país, son pocos los estudios concernientes a la diversidad genética de está especie. Ladiversidad delos aislados de P.vivax ha sido previamente estudiada por análisis de PCR -RFLP del gen Pvmsp $3 \alpha$ en la localidad de Tierralta (16), donde se encontró un alto grado de diversidad genética.

Con la enzima Alu I se identificaron 10 haplotipos para el gen Pvmsp $3 \alpha$, mientras que con la enzima Hha I el número de haplotipos identificados fue de 9 . El número total de haplotipos fue similar en Brasil ( $\mathrm{n}=11$, (17), Guyana Francesa $(n=11,(18))$, Colombia ( $=9$, (19)) y Venezuela $(n=9,(20))$, pero fue ligeramente inferior a lo encontrado en Perú ( $\mathrm{n}$ $=17$, Sutton et al. 2009). Las comparaciones entre haplotipos resultan más difíciles que entre los genotipos, debido a las diferencias entre los tamaños de los fragmentos de restricción reportados en cada estudio. Sin embargo, podríamos identificar aproximadamente siete haplotipos, que se describieron anteriormente, incluyendo el haplotipo para el genotipo C, que tiene el mismo perfil de digestión en todos los estudios reportados en estudios anteriores. Al comparar los perfiles de fragmentos, los haplotipos similares a los descritos aquí fueron las siguientes: nueve de Colombia (Cristiano et al 2008), tres de Perú (21), tres de Brasil (18), cuatro de PNG (22) y seis de Tailandia (23). Estos hallazgos sugieren una distribución global de los parásitos que presentan genotipos similares para el gen Pumsp $3 \alpha$.

Los resultados de la restricción enzimática de las 61 muestras analizadas revelaron que $15 / 61(35,3 \%)$ y $20 / 61(41,6 \%)$ de estas muestras, presentaban infecciones policlonales cuando se les digería con la enzima Alu I y Hha I, respectivamente. Esto demuestra que, en regiones donde un genotipo particular predomina, los resultados de la PCR no son suficientes para hacer una correcta clasificación del tipo de infección presente en unamuestra. Se deberesaltarlaimportancia de utilizar al menos dos enzimas de restricción, ya que, en algunos casos, las muestras que inicialmente habían sido clasificadas como infecciones simples con base en los resultados de la digestión con una de las enzimas, fueron posteriormente identificadas como infecciones policlonales con la segunda enzima.

Como se ha demostrado anteriormente, una alta diversidad genética se puede encontrar incluso en zonas de baja transmisión de P.vivax (24). Por consiguiente, no es sorprendente que los aislados cordobeses descritos aquí sean igualmente diversos como los descritos en las zonas hiperendemicas de PNG (25). En $P$. falciparum, se ha demostrado una correlación mucho más clara entre la endemicidad de la malaria y la variabilidad genética del parásito (26), lo cual ha sido mas difícil en Plasmodium vivax, hechoquepareceradicarenlasdiferencias biológicas entre estos dos parásitos, dado que este último puede presentar durante su ciclo de vida recaídas y gamotocitogenesis. Estos factores pueden favorecer la recombinación meiótica de diferentes haplotipos de parásitos en el mosquito vector $(27,28)$.

Debido a que el análisis de PCR - RFLP del gen Pvmsp $3 \alpha$ detecta sólo polimorfismos en los sitios de restricción de la enzima elegida, su eficiencia para identificar infecciones por múltiples clones es baja, por lo que se recomienda que para futuros estudios se emplee en paralelo con marcadores de ADN neutros, como los microsatélites.

En conclusión, nuestros resultados indican que el gen Pvmsp $3 \alpha$ es un marcador adecuado para el análisis de la epidemiología molecular de aislados de campo de P.vivax, que tiene a su favor su sencillez y bajo costo en comparación con los métodos que análisis de repeticiones en 
tándem, microsatélites o SNPs. Además, no hay ninguna interferencia cuando una coinfección por P.falciparum está presente.

\section{CONCLUSIONES}

- En el estudio, se observó una alta diversidad genética en las poblaciones circulantes de $P$. vivax en el departamento de Córdoba usando comomarcadorel gen Pumsp-3 $\alpha$, tantoenpacientes complicados como no complicados.

- El patrón de restricción PA1 obtenido con la enzimaAlul, sugiereserunpredictorgenético de gravedad en pacientes con malaria.

- Los resultados de este estudio se pueden usar comodatos de referencia para adelantar futuraslasinvestigacionesenel departamento.

- Estos resultados contribuyen al entendimiento de la transmisión de la malaria en Colombia y podrán ser útiles en el desarrollo de estrategias de control contra la malaria.

\section{CONFLICTO DE INTERÉS}

Los autores declaran no tener conflicto de interés.

\section{REFERENCIAS}

1. Ariey F, Hommel D, Le Scanf C, Duchemin JB, Peneau C, Hulin A, et al. Association of severe malaria with a specific Plasmodium falciparum genotype in French Guiana. J Infect Dis 2001, 184(2):237-41.

2. ArnottA, BarryA, Reeder J. Understanding the population genetics of Plasmodium vivax is essential for malaria control and elimination. Malaria Journal 2012, 11:14

3. Bharti P, Mishra AK, Chand SK, Singh

N. "Epidemiology of Malaria in an area of Low Malaria Transmission in Central India." Abstrat Book. American Society of Tropical Medicine and Hygiene 54th Annual Meeting 2005, 73(6): 125.
4. Boletín vigilancia de la malaria en Colombia 2-2015 [http:// www 2. paho.org / COL / index. php?option=com_docman\&task $=d o c$ download\&gi $d=1175 \&$ ttemid=]

5. Bozdech Z, Mok S, Hu G, Imwong $M$, Jaidee $A$, et al. The transcriptome of Plasmodium vivax reveals divergence and diversity of transcriptional regulation in malaria parasites. Proc Natl Acad Sci U S A 2008, 105: 16290-16295.

6. Bruce MC, Galinski MR, Barnwell JW, Snounou G, Day KP. Polymorphism at the merozoite surface protein-3alpha locus of Plasmodium vivax: global and local diversity. Am J Trop Med Hyg 1999; 61: 518-25.

7. Carmona-Fonseca J, MaestreA. Incidencia de la malaria gestacional, congénita y placentaria en Urabá (Antioquia, Colombia), 2005-2007. Rev Colomb Obstet Ginecol 2009, 60:12-26.

8. Carter R, Mendis $\mathrm{KN}$ : Evolutionary and historical aspects of theburden of malaria. Clinical microbiology reviews 2002, 15(4):564-594.

9. Chaparro P., 2007. "Informe final de malaria, semanas 1 a 52 Colombia, 2007." Informe Quincenal Epidemiológico Nacional 2008; 13(4):49-64)..

10. Cowman AF, Crabb BS: Invasion of red blood cells by malaria parasites. Cell 2006, 124(4):755-766.

11. Cristiano FA, Pqrez MA, Nicholls RS, Guerra AP. Polymorphism in the Plasmodium vivax msp 3a gene in field samples from Tierralta, Colombia. Mem Inst Oswaldo Cruz 2008; 103: 493-6.

12. Padilla J, PeñaS. Situación epidemiológica de la malaria en Colombia. Informe Quincenal Epidemiológico Nacional 2002; 7(19):333-346. 
13. Polley SD, Tetteh KK, Lloyd JM, Akpogheneta OJ, Greenwood BM, Bojang KA, Conway DJ: Plasmodium falciparum merozoite surface protein 3 is a target of allele-specific immunity and alleles are maintained by natural selection. The Journal of infectious diseases 2007, 195(2):279-287.

14. Prajapati SK, Joshi $H$, Valecha $N$. Plasmodium vivax merozoite surface protein-3a: a high- resolution marker for genetic diversity studies. JVector Borne Dis 2010; 47: 85-90.

15. Price RN, Tjitra E, Guerra CA, Yeung S, White NJ, Anstey NM: Vivax malaria: neglected and not benign. The American journal of tropical medicine and hygiene 2007, 77(6 Suppl):79-87.

16. Puentes A, Garcia J, Ocampo M, Rodriguez L, Vera R, Curtidor H, Lopez R, Suarez J, Valbuena J, Vanegas $M$ et al: P. falciparum: merozoite surface protein- 8 peptides bind specifically to human erythrocytes. Peptides 2003, 24(7):1015- 1023.

17. Puentes $A$, Ocampo $M$, Rodriguez LE, Vera $R$, Valbuena J, Curtidor H, Garcia J, Lopez R, Tovar D, Cortes J et al: Identifying Plasmodium falciparum merozoite surface protein-10 human erythrocyte specific binding regions. Biochimie 2005, 87(5):461-472.

18. Ribeiro RS, Ladeira L, Rezende $\mathrm{aM}$, Fernandes CJ, Carvalho LH, Ferreira

C. analysis of the genetic variability of PvMSP-3 $\alpha$ among Plasmodium vivax in Brazilian field isolates. Mem Inst oswaldo Cruz, Rio de Janeiro. 2011; 6:27-33.

19. Richie TL, Saul A: Progress and challenges for malaria vaccines. Nature 2002, 415(6872):694-701.

20. Rodriguez-Morales AJ, Delgado L, Martinez N, et al. Impact of imported malaria on the burden of disease in northeastern Venezuela. J Travel Med 2006; 13:15-20.

21. Roshanravan B, et al. 2003. Endemic malaria in the Peruvian Amazon region of Iquitos. Am. J. Trop. Med. Hyg. 69:45-52.

22. Bozdech Z, Mok S, Hu G, Imwong M, Jaidee A, et al. (2008) The transcriptome of Plasmodium vivax reveals divergence and diversity of transcriptional regulation in malaria parasites. Proc Natl Acad Sci U S A 105: 16290-16295.

23. Bruce MC, Galinski MR, Barnwell JW, Snounou G, Day KP. Polymorphism at the merozoite surface protein-3alpha locus of Plasmodium vivax: global and local diversity. Am J Trop Med Hyg 1999; 61: 518-25.

24. Carmona-Fonseca J, Maestre A (2009). Incidencia de la malaria gestacional, congénita y placentaria en Urabá (Antioquia, Colombia), 2005-2007. Rev Colomb Obstet Ginecol. 60:12-26.

25. Carter R, Mendis KN: Evolutionary and historical aspects of the burden of malaria. Clinical microbiology reviews 2002, 15(4):564-594.

26. Cristiano FA, Pqrez MA, Nicholls RS, Guerra AP. Polymorphism in the Plasmodium vivax msp $3 \mathrm{a}$ gene in field samples from Tierralta, Colombia. Mem Inst Oswaldo Cruz 2008; 103: 493-6.

27. Cui L, Mascorro CN, Fan Q, Rzomp KA, et al. Genetic diversity and multiple infections of Plasmodium vivax malaria in western Thailand. Am J Trop Med Hyg 2003; 68: 613-9. de Souza-Neiras WC, de Melo LM, Machado RL: The genetic diversity of Plasmodium vivax--a review. Memorias do Instituto Oswaldo Cruz 2007, 102(3):245-254.

28. Duarte EC, Gyorkos TW, Pang L, Abrahamowicz M. Epidemiology of malaria in a hypoendemic Brazilian Amazon migrant population: A cohort study. Am J Trop Med Hyg. 2004; 70:229-37. 